\title{
Response of Cowpea, Soya Beans and Groundnuts to Non-Indigenous Legume Inoculants
}

\author{
Alice Mutiti Mweetwa ${ }^{1}$, Malama Mulenga ${ }^{2}$, Xaviour Mulilo ${ }^{1}$, Munsanda Ngulube ${ }^{1}$, John S. K. Banda ${ }^{1}$, \\ Ndashe Kapulu ${ }^{3} \&$ Shirley Handia N'gandu ${ }^{2}$ \\ ${ }^{1}$ Department of Soil Science, School of Agricultural Sciences, University of Zambia, Lusaka, Zambia \\ ${ }^{2}$ Department of Plant Science, School of Agricultural Sciences, University of Zambia, Lusaka, Zambia \\ ${ }^{3}$ Soil Microbiology Laboratory, Zambia Agricultural Research Station, Zambia \\ Correspondence: Alice Mutiti Mweetwa, Department of Soil Sciences, School of Agricultural Sciences, \\ University of Zambia Box 32379, Lusaka, Zambia. Tel: 260-971-803-918. E-mail: alicemweetwa@yahoo.com
}

\author{
Received: September 8, 2014 Accepted: October 5, 2014 Online Published: October 9, 2014 \\ doi:10.5539/sar.v3n4p84 URL: http://dx.doi.org/10.5539/sar.v3n4p84
}

\begin{abstract}
The use of inoculants is a critical strategy in legume production. In Zambia, inoculants are particularly used for the production of non-promiscuous genotypes of soya beans, but rarely for cowpeas and groundnuts. This study evaluated the response of soya beans, cowpeas and groundnuts to Biofix legume inoculants. Seeds were inoculated at the recommended or double the recommended rate at planting. Plants were grown under greenhouse conditions in a Completely Randomized Design for 7 weeks. Control, non-inoculated seeds were also planted and plants grown under the same conditions. At 7 weeks, nodule number and fresh weight per plant, nodule effectiveness (pinkness/redness), and above ground biomass were determined. Biologically fixed nitrogen was determined using the Nitrogen Difference Method. Nodule number and fresh weight per plant were higher at the recommended rate of Biofix application for soya beans and at both rates for groundnuts, while there was no effect on nodule fresh weight at either rate in cowpeas. All representative nodules assessed were effective. There was no significant benefit in inoculating seeds of the three legumes with Biofix on above ground biomass and biological nitrogen fixation. These results could suggest that possibly, the introduced strains though with a stronger nodulation competitiveness, were not as effective at fixing nitrogen as the indigenous strains in the soils in which soya beans, cowpeas and groundnuts have been repeatedly grown before. This could be an indication that sufficient and appropriate effective strains are already present in this soil. In general, the results suggest that to obtain the full benefits of biological nitrogen fixation, legume growers need to be provided with the correct inoculant, where required. Further work under field conditions is recommended to confirm these findings.
\end{abstract}

Keywords: biofix, inoculant, Nitrozam, legume, Zambia

\section{Introduction}

Legumes are a cheap source of dietary protein, energy, oils and vitamins for humans and animals. They are also of agricultural benefit in that they have the ability to improve the fertility of soil through biological nitrogen fixation (BNF) (Herridge, 2002). In Zambia, legume production is second only to cereal production and is growing rapidly, with groundnuts (Arachis hypogeae), soya beans (Glycine max) and cowpea (Vigna unguiculata) among the leading legumes. These legumes are grown across the country, with cowpea production concentrated in Northern and Southern provinces, soya beans in Central province and groundnuts in Eastern province (Ross \& de Klerk, 2012).

Poor legume productivity on most small holder farms in sub-Saharan Africa is due to declining soil fertility and as a result of poor soil management practices (Chianu, Nkonya, Mairura, Chianu, \& Akinnifesi, 2010; Balume, 2013). Farmers use strategies such as application of organic and inorganic fertilizers, phosphate rocks and Rhizobium inoculants (Mungai \& Karubiu, 2010) to address challenges of low soil fertility. The use of inorganic fertilizers is effective but costly (Chianu et al., 2010). Organic fertilizers, such as crop residues and animal manures, are bulky and the nutrient quality and release patterns are both variable.

Although the benefits of applying legume inoculants has been known since ancient days (Compro II, 2013), there is still potential for further use to the expand area under production and increase legume yields. The use of 
Rhizobium and Bradyrhizobium inoculants as biofertilizers to improve soil nitrogen by BNF has proven to be economically beneficial (Mungai \& Karubiu, 2010) and necessary in all soils deficient of nitrogen (Chianu et al., 2010).

While Rhizobia appear to be as widely distributed as the legumes themselves, numbers of highly effective rhizobia in soils may be limiting (Herridge, Gemell, \& Hartley, 2002). For example, soils in South Africa have recently been reported to be devoid of strains of rhizobia that can effectively nodulate soya bean roots, necessitating the use of inoculants (Hassen, Bopape, Rong, \& Seane, 2014). In North American, soils in West Texas have been reported to contain very limited populations of rhizobia and bradyrhizobium for effective symbioses with legumes (Radtke, 2003). With the foregoing, inoculation with rhizobia is done to increase the number effective bacteria in the rhizosphere. However, the efficacy of any inoculant is dependent on the capability the rhizobial strains it contains to out-compete the indigenous rhizobia in the soil (Keyser, Somasegaran, \& Bohlool, 1992); an ability termed as 'competiveness' (McDermott \& Graham, 1990). It is important to ensure that soils are inoculated with high numbers of rhizobia that eventually colonise the rhizosphere (Herridge et al., 2002; Deaker, Roughly, \& Kennedy, 2004). This is typically achieved by using good quality inoculants containing large numbers of viable rhizobia and using higher-than-recommended rates of inoculation. Additionally, minimising the death of rhizobia between the times the seed or soil is inoculated and when nodulation occurs is a potential strategy that also ensures that high numbers of viable rhizobia nodulate the seedlings. Though each of these approaches has its own merit, using high-quality inoculants gives consistent results (Brockwell, Bottomley, \& Thies, 1995).

Unlike Kenya, Malawi and Zimbabwe, limited work has been done in Zambia on the types of inoculants that can be used to inoculate groundnuts, soya beans and cowpeas. The earliest documented work on the inoculation of legumes in Zambia was in the mid- 60s; this work culminated into a pilot programme at Mount Makulu Research Station for the production of a commercial inoculant for soya bean almost ten years later (Bala et al., 2011). In Kenya, Biofix, a commercial peat-based inoculant was developed in 1981(Woomer, Chamwada, Kaleha, Omondi, \& Ongoma, 2012). This is the most available and commonly used inoculant by farmers in Kenya (Compro II, 2013). Because of its composition, it is suitable for inoculating common beans, soya beans, cowpea, groundnuts and legume trees. According to Woomer et al. (2012), all varieties in Kenya respond positively to inoculation with Biofix. Therefore, Biofix is a very promising inoculant that would be useful to low nitrogen soils in other countries, such as Zambia. Here, an opportunity exits to evaluate the performance of Biofix in Zambian soils and potentially promote it locally. This study was conducted to evaluate the performance of Biofix inoculants for biological nitrogen fixation in soya beans, cowpeas and groundnuts in Zambian soils.

\section{Materials and Methods}

\subsection{Soil Collection and Characterization}

Soil used in this study was collected from the University of Zambia field station, Lusaka. The area receives an average annual rainfall of about $800-1000 \mathrm{~mm}$, typical of Region II of Zambia. The soil was randomly collected from six representative points at a depth of $15 \mathrm{~cm}$ using an auger. These samples were then mixed to make a composite sample. Standard laboratories procedures were used to analyse the soil samples for exchangeable bases $\left(\mathrm{Ca}^{2+}, \mathrm{Mg}^{2+}\right.$ and $\left.\mathrm{K}^{+}\right)$(Rowell, 1994), available phosphorus (Olsen et al., 1954), soil pH (Van Reeuwijk, 1992) and total nitrogen (Bremner \& Mulvaney, 1982). The soil characteristics are shown in Table 1.

Table 1. Selected chemical characteristics of soils used in the greenhouse trial

\begin{tabular}{|c|c|c|c|c|c|c|}
\hline $\begin{array}{c}\text { Soil } \\
\text { Characteristic }\end{array}$ & $\begin{array}{c}\mathrm{pH} \\
\left(\mathrm{CaCl}_{2}\right)\end{array}$ & $\begin{array}{c}\text { Phosphorus } \\
\text { (mg/kg) }\end{array}$ & Potassium & Calcium & Magnesium & $\begin{array}{c}\text { Total } \\
\text { Nitrogen }(\%)\end{array}$ \\
\hline & & \multicolumn{5}{|c|}{$. . \mathrm{Cmol}(+) / \mathrm{kg} \ldots \ldots \ldots \ldots \ldots \ldots$} \\
\hline & 5.14 & 13.44 & 0.35 & 3.95 & 0.83 & 0.098 \\
\hline
\end{tabular}

\subsection{Greenhouse Evaluation of Biofix Performance}

Three legumes commonly grown in Zambia, soya beans, cowpeas and groundnuts, were used in this trial. The varieties for soya beans, groundnuts and cowpeas grown were Lukanga (non-promiscuous genotype), Makulu Red and Bubebe, respectively. The crops were grown in pots with $4 \mathrm{~kg}$ of soil under greenhouse conditions. At planting, seeds of all the three legumes were inoculated with Biofix at the recommended rate and at double the rate. In addition, Nitrozam, a locally produced Bradyrhizobium japonicum inoculant was also inoculated on soya 
beans at the two rates. The evaluation also included non-inoculated controls. In order to evaluate total nitrogen fixed by the three legumes, Pearl millet (Pennisetum glaucum) was included as a reference crop. The trial was arranged as a Completely Randomized Design with four replications and grown for seven weeks before harvesting and data collection.

\subsection{Determination of Nodule Number, Nodule Fresh Weight and Nodule Effectiveness}

At seven weeks after planting, plants were carefully uprooted from the pots and placed on sieves to avoid loss of nodules during cleaning. The soil was then gently washed off the roots under a stream of running tap water. The nodules were then carefully removed from the roots, counted and weighed. Representative nodules from each treatment were cut to determine pinkness as an indicator of effectiveness.

\subsection{Determination of Biologically Fixed Nitrogen and Above Ground Biomass Yield}

The above ground biomass was determined as an average of the four replications after drying to a constant weight at $65^{\circ} \mathrm{C}$. Total nitrogen fixed was determined using the Nitrogen Difference Method of Unkovich et al. (2008). In this method, legumes in all the treatments were grown under greenhouse conditions alongside the non $\mathrm{N}$ fixing reference crop, Pearl millet. At seven weeks, percent tissue $\mathrm{N}$ was determined in all plants using the modified Kjeldahl method. The percent nitrogen fixed was then determined by calculating the difference between the $\mathrm{N}$ in the legumes and that in the reference crop. In order to account for the nitrogen that remained in the roots and/or was lost in the soil, the calculated valued was then multiplied by a factor of 1.5.

\subsection{Data Management and Statistical Analyses}

Data were collected in replicates of four and analysed using SAS Statistical Package Version 9.1. To determine the effects due to inoculation, Analysis of Variance at $95 \%$ confidence limit was done and means separated using the Least Significance Difference (LSD).

\section{Results}

\subsection{Effect of Biofix Legume Inoculants on Nodule Number, Nodule Fresh Weight Per Plant and Nodule Effectiveness}

Inoculation of soya beans, cowpeas and groundnuts with Biofix showed varied responses with respect to number of nodules per plant. Number of nodules ranged from 19 to 30 in soya beans plants across the treatments. Plants inoculated at the normal rate with Nitrozam had the highest number of nodules per plant (Figure 1). The results also showed that Biofix applied at the recommended rate in soya beans resulted in significantly more nodules per plant than the (control) uninoculated plants. However, there was no increase in number of nodules per plant when the Biofix application rate was doubled. The results also showed that inoculation with Nitrozam resulted in more nodules per plant than with Biofix at both application rates.

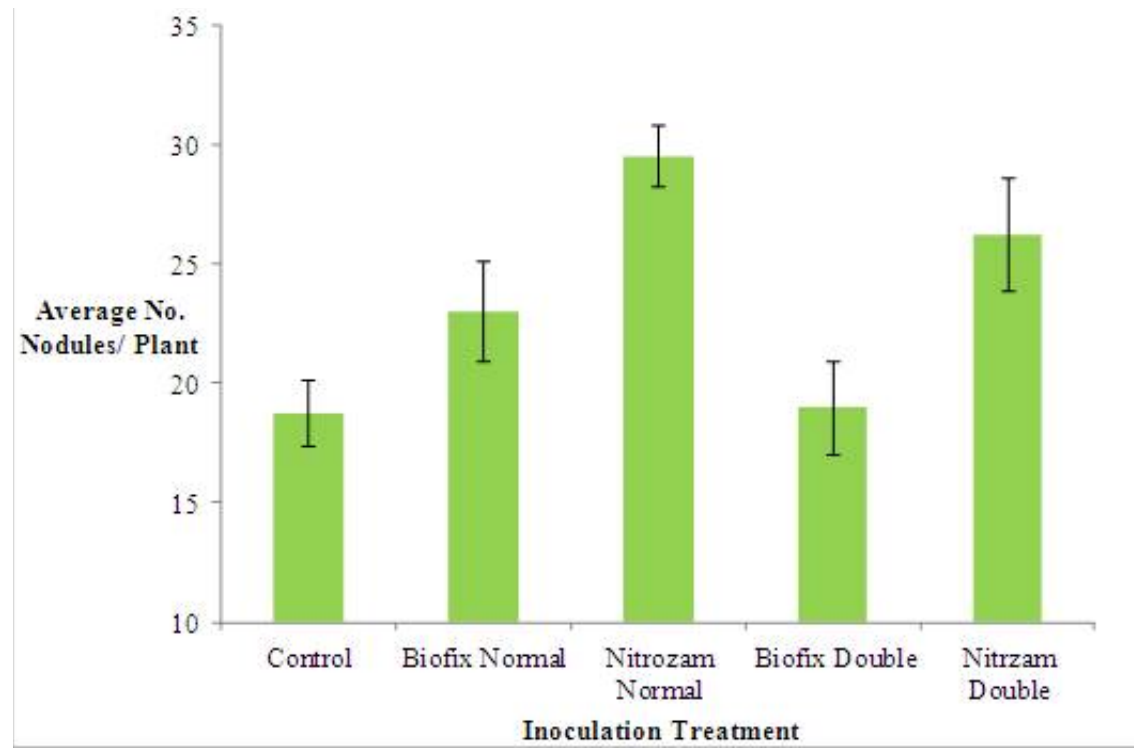

Figure 1. Effect of BIOFIX and Nitrozam inoculation on average nodule number per plant in soya beans at 7 weeks after planting 


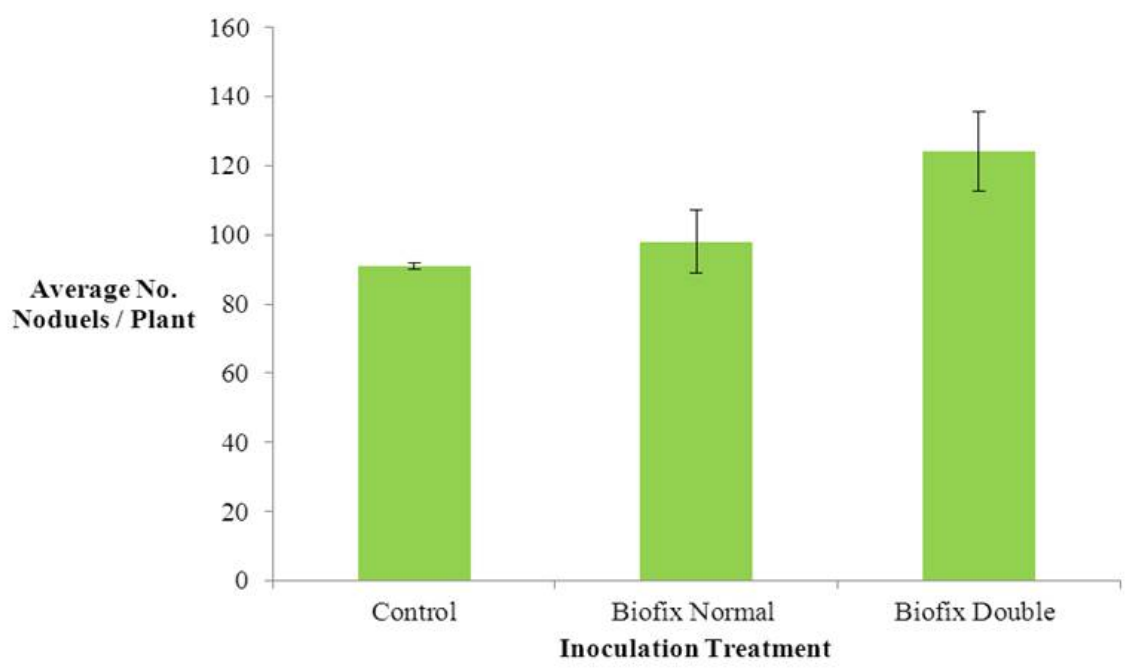

Figure 2. Effect of BIOFIX inoculation on average nodule number per plant in cowpeas at 7 weeks after planting

In cowpeas, the number of nodules per plant ranged from 91 to 124 across treatments (Figure 2). Inoculating cowpea seeds with Biofix at the normal rate did not result in significantly more nodules per plant while doubling the rate resulted in a $36 \%$ increase.

The number of nodules per plant in groundnuts ranged from 82 to 252 across treatments. Inoculating groundnut seeds with Biofix at the normal and double rates resulted in significantly more nodules per plant (Figure 3 ).

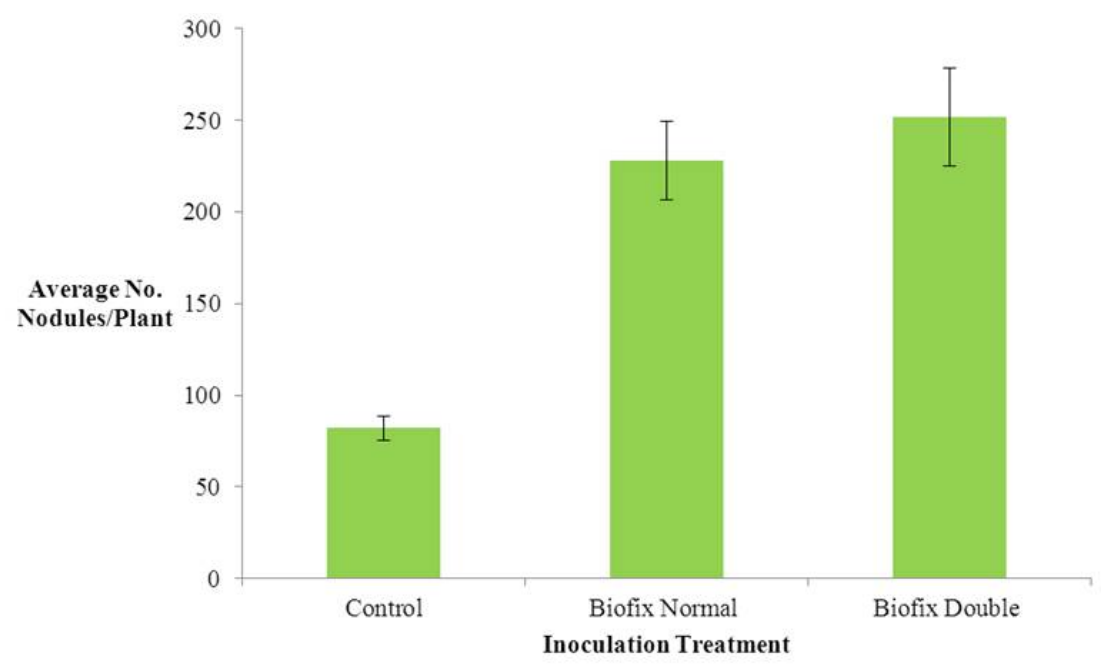

Figure 3. Effect of BIOFIX inoculation on average nodule number per plant in groundnuts at 7 weeks after planting 


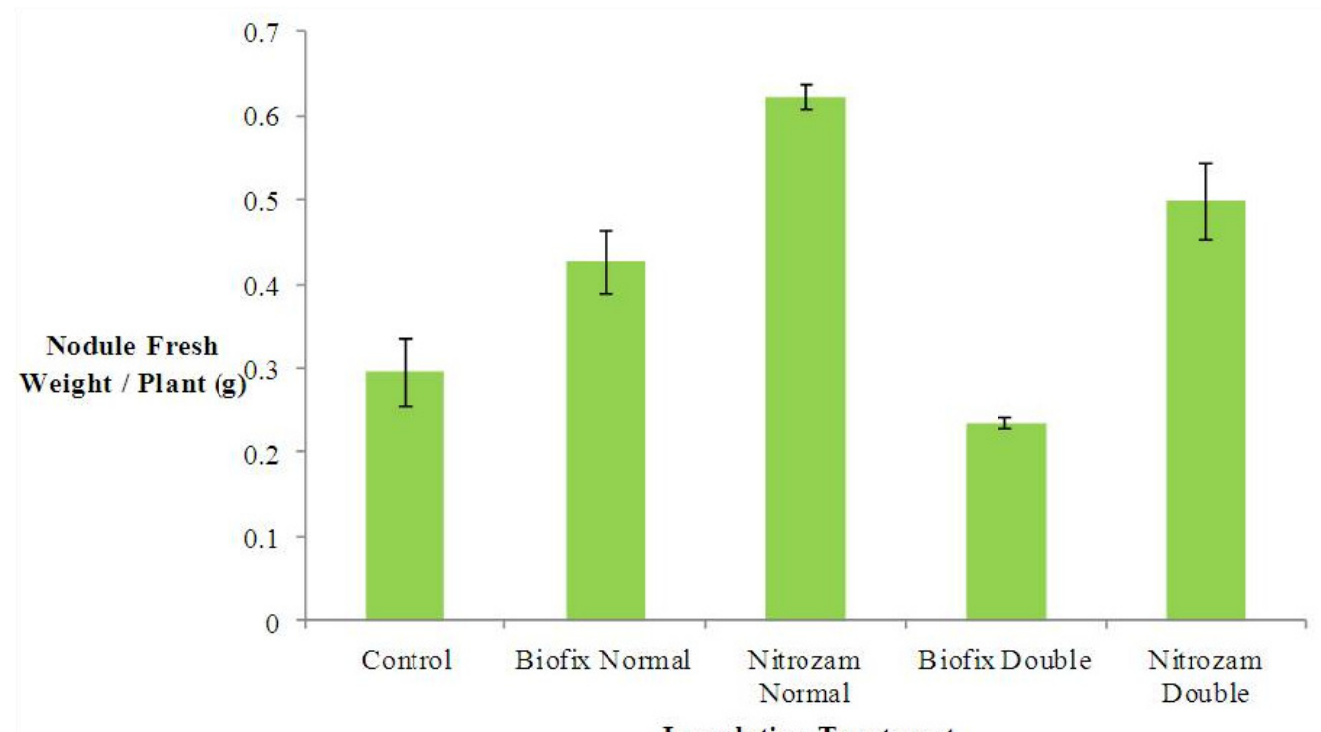

Figure 4. Effect of BIOFIX and Nitrozam inoculation on average nodule fresh weight per plant in soya beans at 7 weeks after planting

Just as the number of nodules per plant, the response of soya beans, cowpeas and groundnuts to inoculation also varied with respect to nodule fresh weight per plant. In soya beans, inoculation with Nitrozam at both rates resulted in significantly higher nodule fresh weight than the uninoculated and inoculation with Biofix (Figure 4). Inoculation with Biofix at the normal rate resulted in significantly higher nodule fresh weights than the uninoculated. Inoculating seeds of soya beans with Biofix at the double rate resulted in depressed nodule fresh weights.

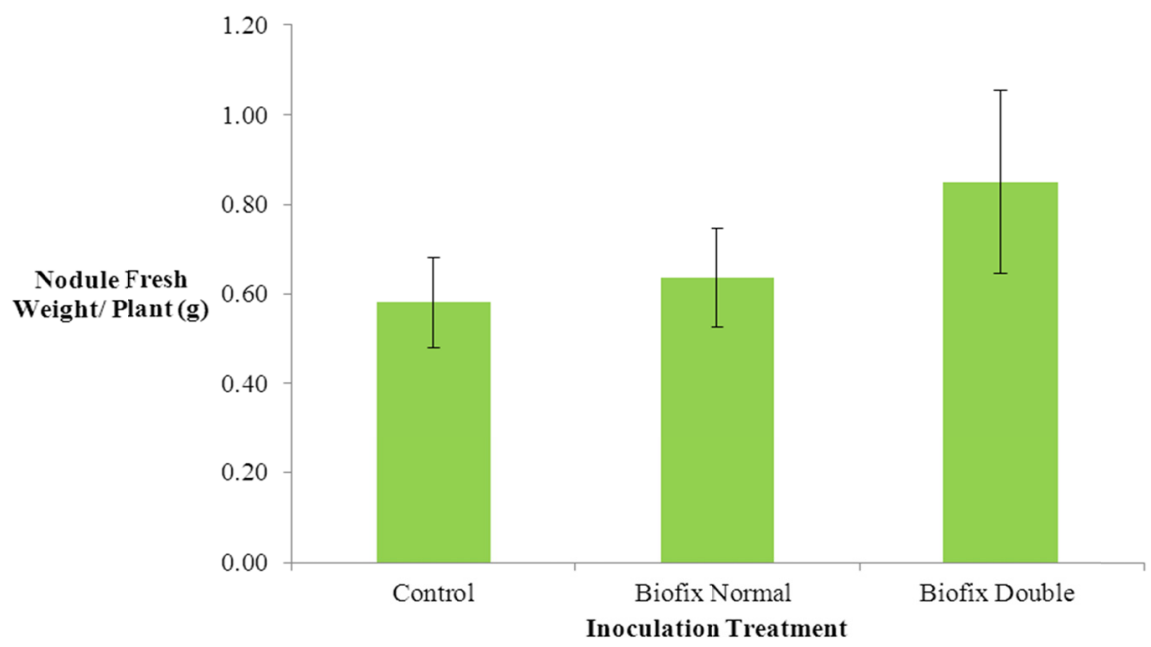

Figure 5. Effect of BIOFIX inoculation on average nodule fresh weight per plant in cowpeas at 7 weeks after planting

Inoculating cowpea seeds with Biofix at the normal and double rates did not result in significantly higher nodule fresh weights per plant (Figure 5). On the other hand, there were increases in nodule fresh weight per plant of 142 and 154\% with Biofix inoculation at the normal and double rates in groundnuts, respectively (Figure 6). The differences in the nodule fresh weight per plant were not significant between the normal and double inoculation rates in groundnuts. 


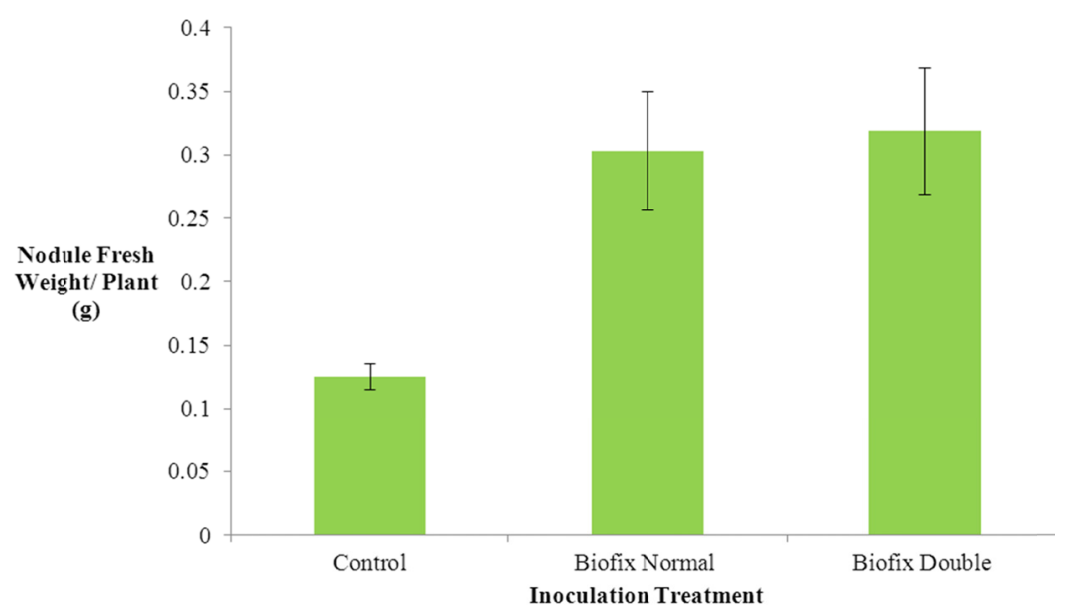

Figure 6. Effect of BIOFIX inoculation on average nodule fresh weight per plant in groundnuts at 7 weeks after planting

All representative nodules from each treatment assessed were pink or red; the results are shown in Figure 7. Based on this, all assessed nodules from all the three legumes were effectively metabolizing dinitrogen at this stage.

A

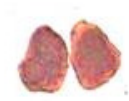

B

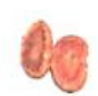

C

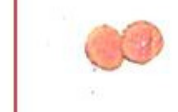

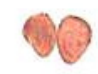
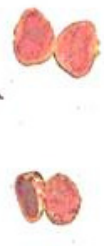
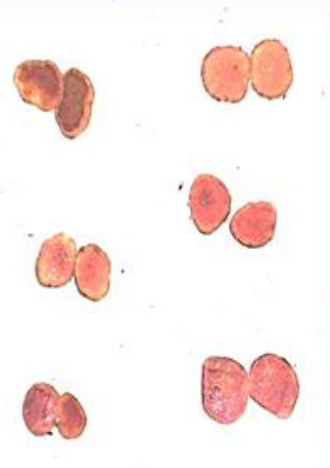

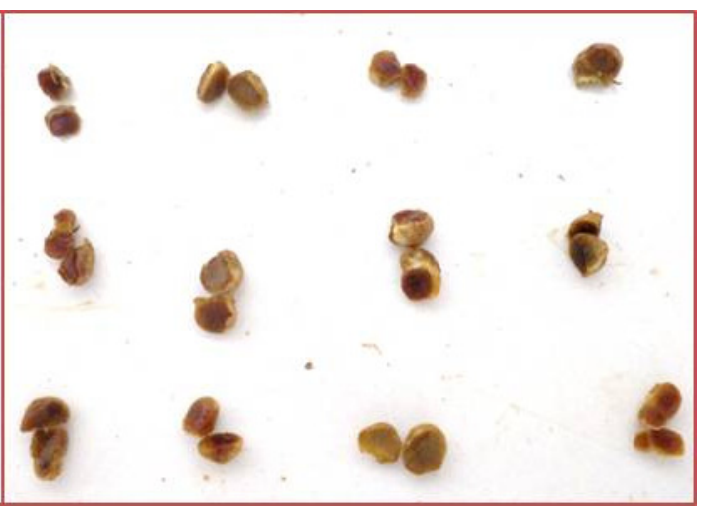

Figure 7. Nodule effectiveness at 7 weeks after planting in soya beans (left panel) and groundnuts (right panel)

3.2 Effect of Biofix Legume Inoculants on Biological Nitrogen Fixation by Cowpea, Soya Beans and Groundnuts Inoculating soya beans, groundnuts and cowpeas with Biofix (and Nitrozam in the case of soya beans) did not significantly change the amount of biologically fixed nitrogen by the seventh week after planting. In the case of soya beans there was no difference in the amount of nitrogen fixed between plants inoculated with Biofix and Nitrozam (Table 2). 
Table 2. Response of biological nitrogen fixation in soya beans, cowpeas and groundnuts to inoculation with Biofix and Nitrozam at normal and double rates

\begin{tabular}{ccccccc}
\hline & \multicolumn{3}{c}{ Inoculation Treatment } \\
& Uninoculated & $\begin{array}{c}\text { Inoculated } \\
\text { Normal-Biofix }\end{array}$ & $\begin{array}{c}\text { Inoculated } \\
\text { Double-Biofix } \\
\text { \% Nitrogen Fixed }\end{array}$ & $\begin{array}{c}\text { Inoculated } \\
\text { Normal- Nitrozam }\end{array}$ & $\begin{array}{c}\text { Inoculated } \\
\text { Double- } \\
\text { Nitrozam }\end{array}$ \\
\hline Soya beans & $6.2 \mathrm{a}^{*}$ & $4.4 \mathrm{a}$ & $6.2 \mathrm{a}$ & $4.4 \mathrm{a}$ & $6.1 \mathrm{a}$ & 1.85 \\
Cowpeas & $4.6 \mathrm{a}$ & $5.4 \mathrm{a}$ & $4.3 \mathrm{a}$ & - & - & 3.02 \\
Groundnuts & $5.1 \mathrm{a}$ & $3.1 \mathrm{a}$ & $3.9 \mathrm{a}$ & - & - & 2.36 \\
\hline
\end{tabular}

*Means followed by the same letter within a row are not significantly different at $95 \%$ confidence level.

3.3 Response of Growth and Biomass Yield of Cowpea, Soya Beans and Groundnuts to Biofix and Nitrozam Inoculants

Results in Figures 8, 9 and 10 show that there was varied growth responses to inoculation by soya beans, cowpeas and groundnuts. In general, there was a reduction in above ground dry weight of soya beans with inoculation with both Biofix and Nitrozam at the double rate, though not significant (Figure 8). In general, inoculating cowpeas and groundnuts did not result in a significant change in above ground dry weight per plant (Figures 9 and 10).

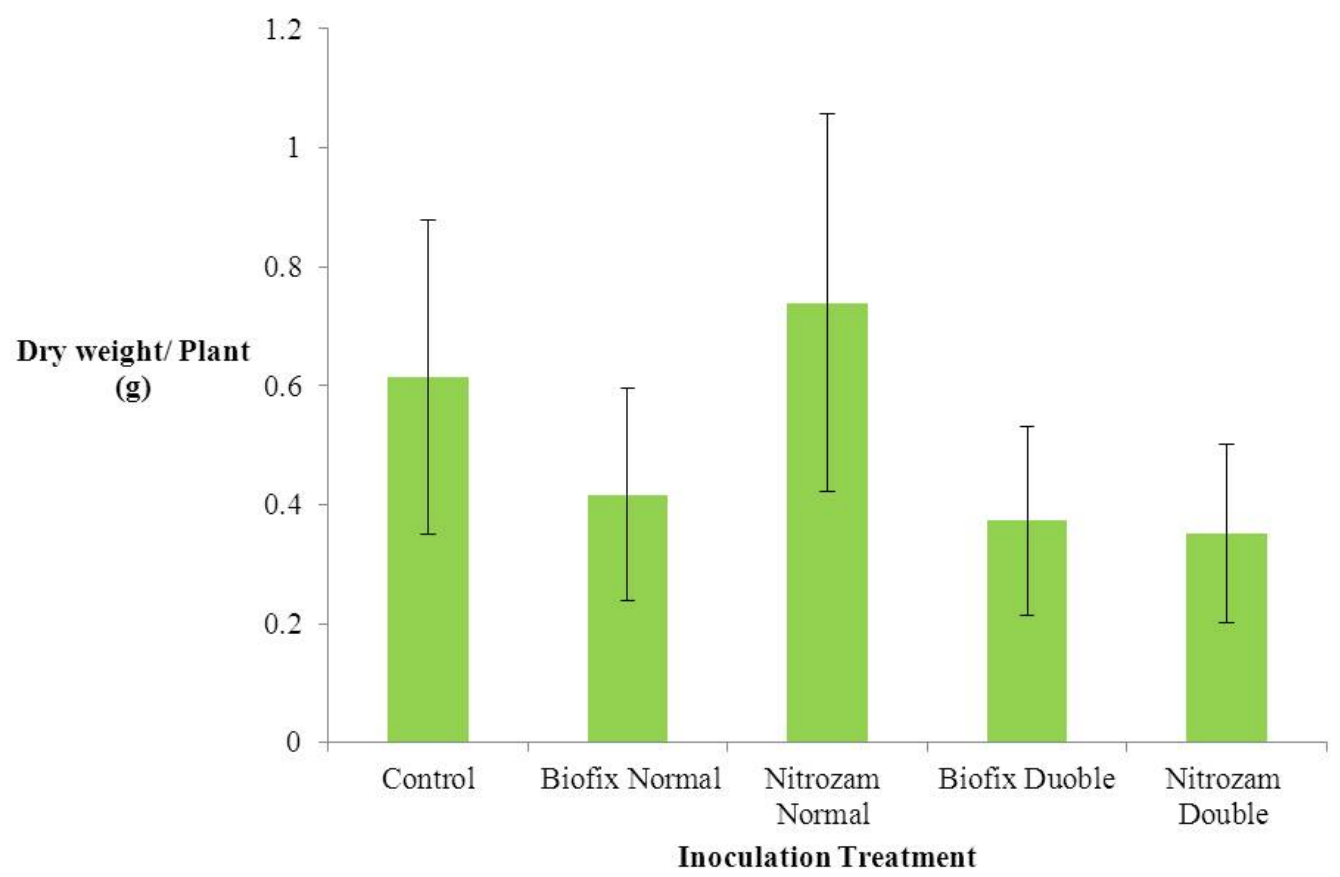

Figure 8. Above ground dry weight of soya beans inoculated with Biofix and Nitrozam at 7 weeks after planting 


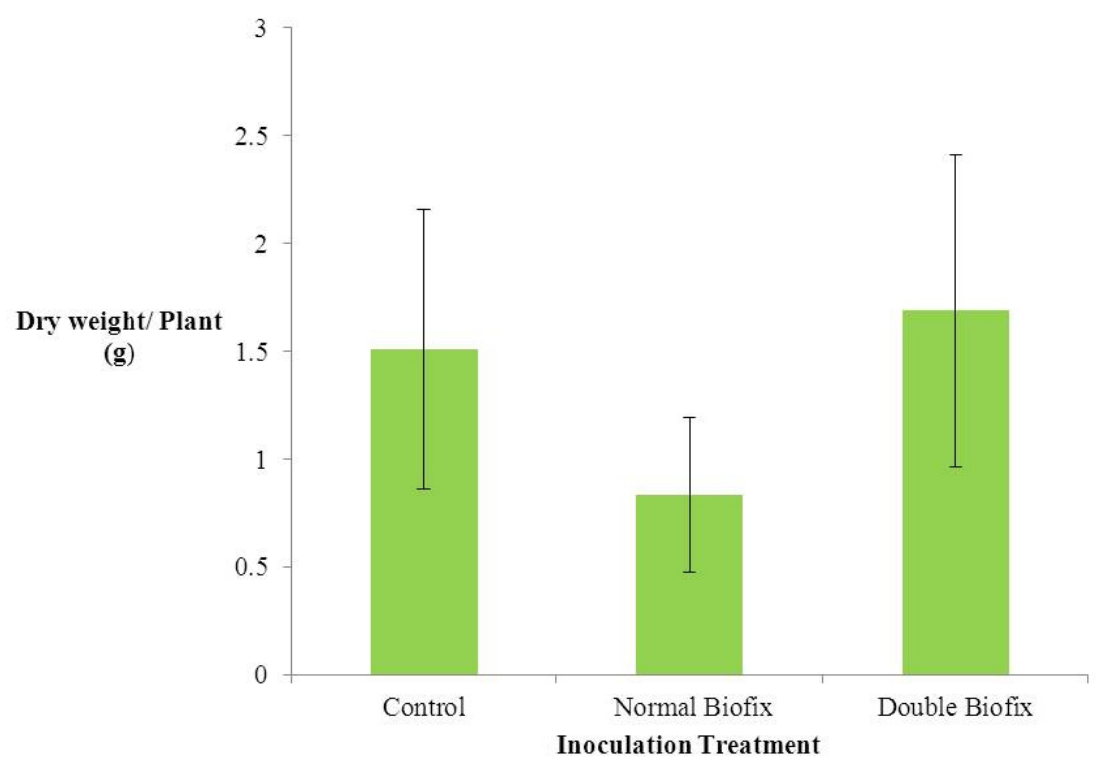

Figure 9. Above ground dry weight of cowpeas inoculated with Biofix at 7 weeks after planting

Observed growth of plants at 5 and 7 weeks after planting (Figure 11), indicated that plant size did not generally differ among the treatments in soya beans and cowpeas. However, bigger leaves were noted in cowpea plants inoculated at the double rate. In groundnuts, the sizes of the plants increased from the uninoculated to the double rate inoculated (Figure 11); this pattern of growth followed that of the observed above ground dry weights per plant (Figure 10).

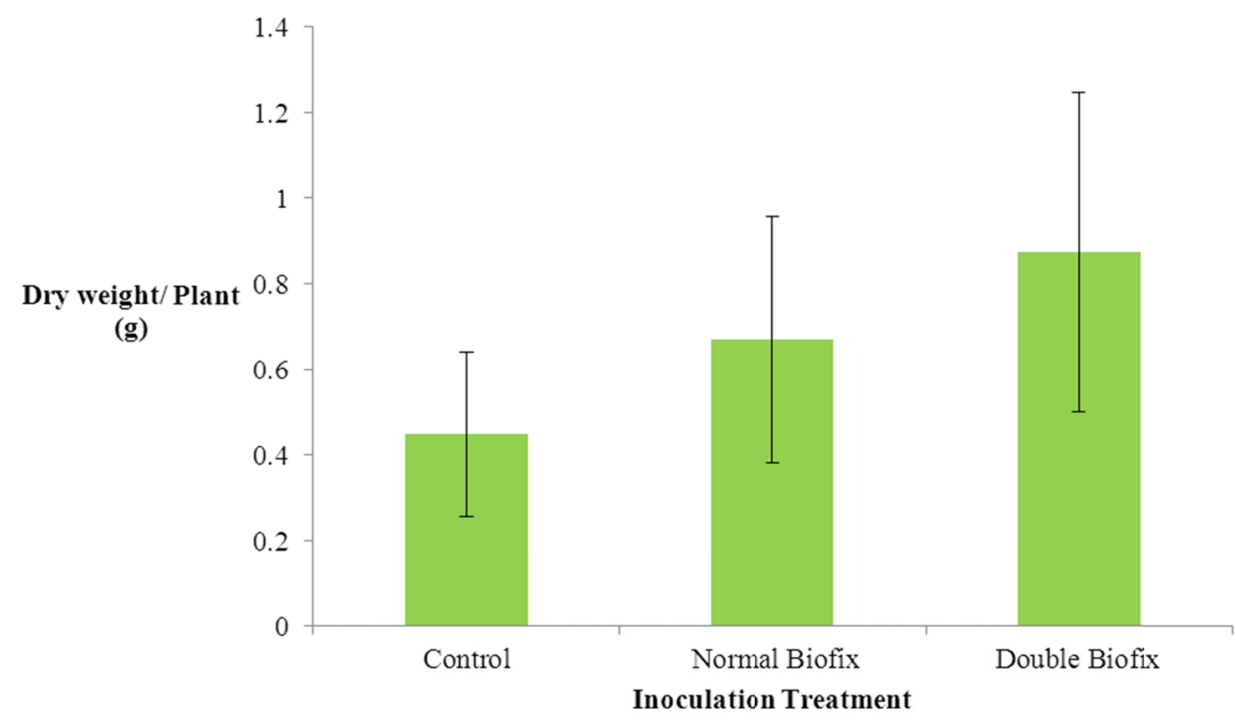

Figure 10. Above ground dry weight of groundnuts inoculated with Biofix at 7 weeks after planting 
Soya beans- Lukanga
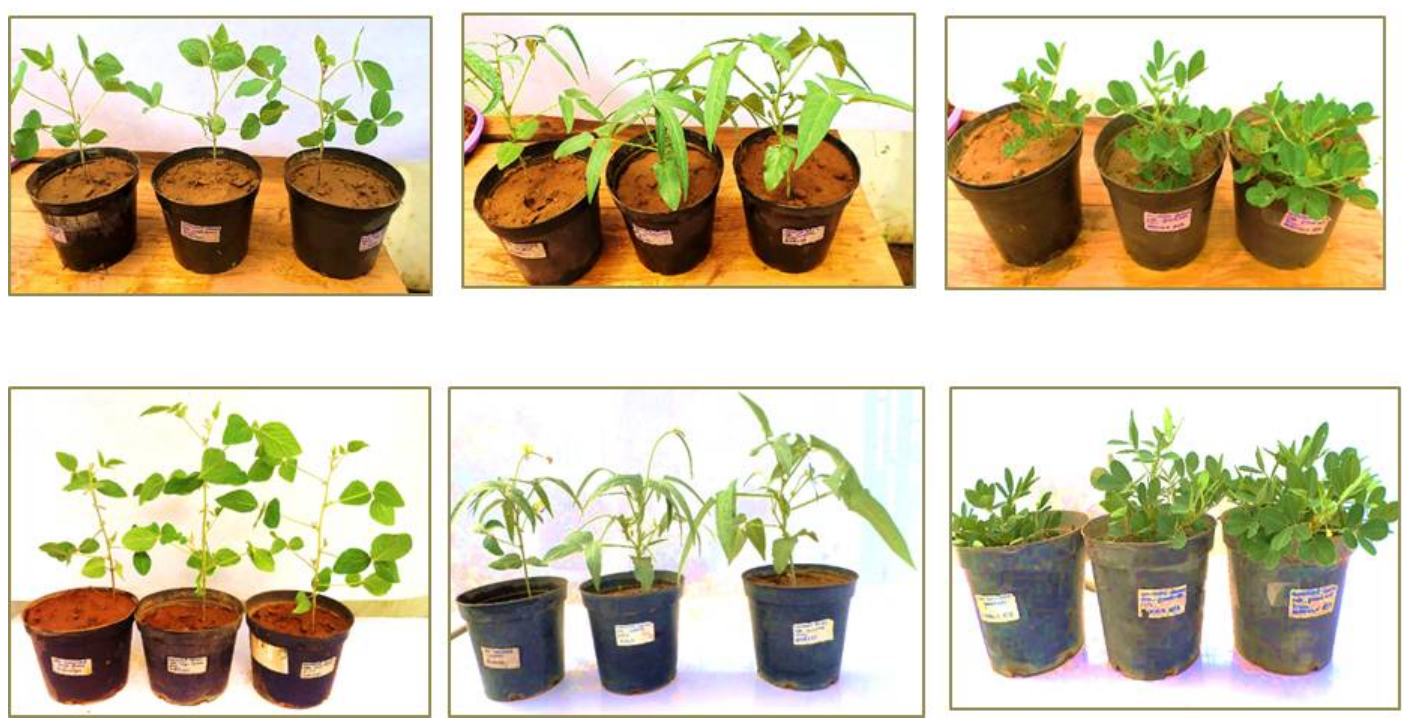

Figure 11. Effect of Biofix inoculation on soya beans, cowpeas and groundnut growth at 5 and 7 weeks after planting

Top: Left to right, soya beans, cowpeas and groundnuts plants (uninoculated, inoculated normal and inoculated double) at 5 weeks after planting. Bottom: Left to right, soya beans, cowpeas and groundnuts plants (uninoculated, inoculated normal and inoculated double) at 7 weeks after planting

An assessment of root growth showed that more root biomass accumulated in plants that were inoculated with Biofix at the normal rate than in the uninoculated and those inoculated at the double rate. Root biomass in all the three legumes was lowest in plants inoculated at the double rate (Figure 12).

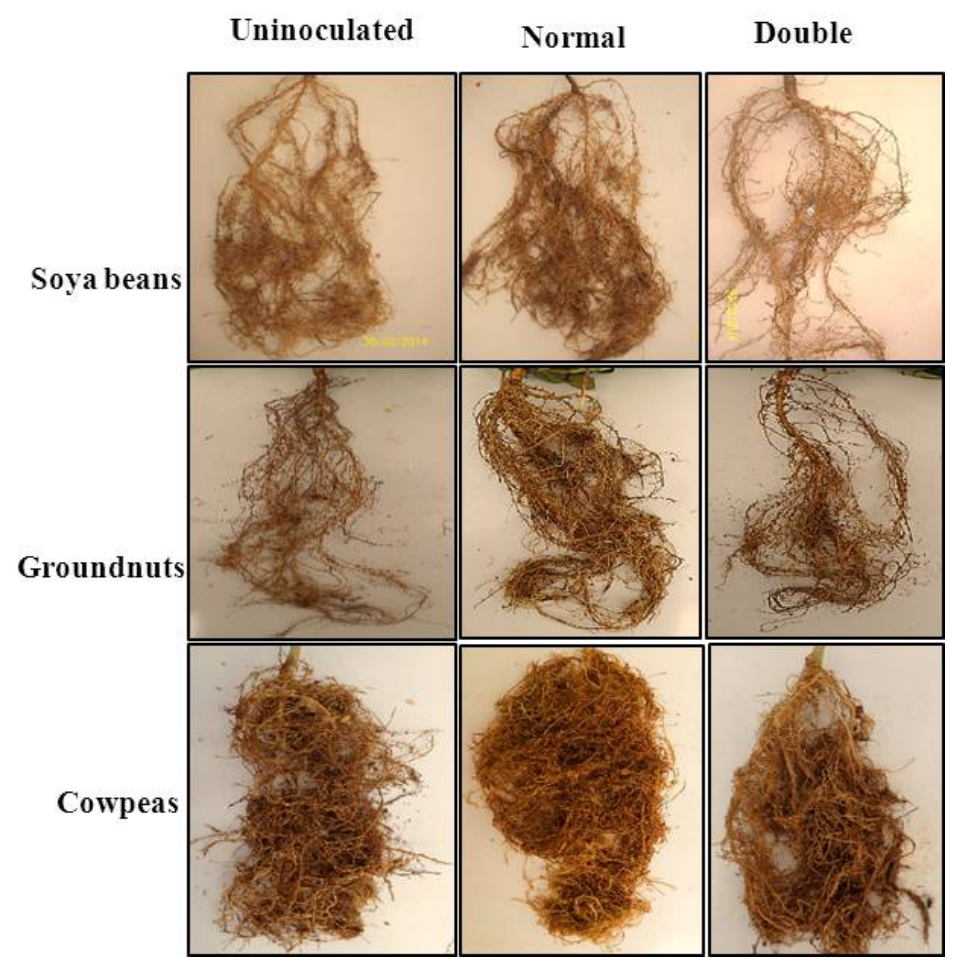

Figure 12. Response of below ground biomass accumulation at 7 weeks after planting to inoculation with Biofix at the normal and double rates 


\section{Discussion}

While soil factors such as soil reaction $(\mathrm{pH})$ and mineral nutrition can have a significant effect on the performance of resident and inoculated rhizobia, soils used in this study were suitable for rhizobia growth in terms of total and available nitrogen, phosphorus and $\mathrm{pH}$ (Table 1). In this case, soil nitrogen was below the critical limit of $0.25 \%$ for crop production which would not inhibit biological nitrogen fixation (Tisdale, Nelson, \& Beaton, 1985); the quantities of phosphorus were sufficient to support nodule growth and activity; and the $\mathrm{pH}$ was above the critical limit of 5 for biological nitrogen fixation (Howieson \& Ballard, 2004).

The varied response of legumes to inoculation with non-indigenous rhizobia has been previously reported. In this study, the results indicate that inoculating both Biofix and Nitrozam on soya bean seeds can increase the number as well as the fresh weight of nodules per plant. Inoculating healthy soya beans plants with Bradyrhizobium japonicum Strain USDA 110 was previously shown to increase the number of nodules per plant (Tu, Ford, \& Grau, 1970; Woomer et al., 2012). The results of this study also show a significant increase in nodulation in both groundnuts and cowpeas with inoculation. With respect to nodule fresh weight, our results indicate an increase of 142 and $154 \%$ in groundnuts, for the normal and double rates, respectively. This observation is despite existing evidence that groundnuts tend to nodulate effectively with native rhizobia because they are highly promiscuous (Castro, Permigiani, Vinocur, \& Fabra, 1999). The results from this study also contrast earlier findings where inoculation with Biofix resulted in a $2.51 \%$ decrease in nodule fresh weight per plant in groundnuts (Compro II, 2012). Inoculation with Biofix did not significantly increase the nodule fresh weight per plant in cowpea, an observation previously reported by Compro II (2012). The varied response to inoculation by soya beans, cowpeas and groundnuts in terms on nodule fresh weight is an indication that the response is crop dependent even if all the three 'Biofix' inoculants applied are based on Bradyrhizobium japonicm.

While nodule number and fresh weight per plant increased with inoculation, our study did not show a corresponding increase in total nitrogen fixed. This suggests that nodule efficiency maybe more important in determining the amount of nitrogen fixed than nodule number or fresh weight (Mungai \& Karubiu, 2010). Previous studies assessing the response of several legumes to inoculation with Biofix revealed that there was generally no significant increase in the amount of total nitrogen accumulated with inoculation, though the response depended on the legume (Compro II, 2012). The total nitrogen accumulated by legumes has even previously been shown to reduce with Biofix inoculation. For example, a $4.13 \%$ reduction was observed by Compro II (2012) in groundnuts. In our study, groundnuts inoculated with Biofix accumulated $65 \%$ less total nitrogen compared to the controls, though not statistically significant.

The lack of a positive relationship between nodulation and the amount of nitrogen fixed maybe an indication that while the inoculated strains maybe more competitive than the indigenous strains, they may not necessarily be highly effective at fixing nitrogen. In this case, we roughly define nodulation competiveness as being the 'ability of a given strain to dominate nodulation in the presence of other strains of the same species' (Castro et al., 1999). Studies in several legumes including the ones studied here, have shown that a majority of nodules maybe occupied with moderately effective strains in the inoculant, rendering more effective soil strains incapable of establishing themselves and this, resulting in unimproved or even reduced nitrogen fixation and biomass yield (Singleton \& Tavares, 1986). Additionally, plants will resist infection of a contrasting organism if already infected with another (Waksman, 1952).

The results of the study indicate that biomass yield and growth of the legumes were not affected by inoculation. This tallies with the observed non-responsiveness of biological nitrogen fixation to inoculation. This is explained by the fact that enhanced growth of the legumes is mainly due to nitrogen fixed by rhizobia. Previous work has also shown that inoculation with Biofix did not result in significant changes in above ground biomass in cowpeas and groundnuts (Compro II, 2012) or any increase in shoot dry biomass nor nodule weights in common beans (Mungai \& Karubiu, 2010).

Where ineffective populations of rhizobia exist in the soil, high numbers of effective rhizobia to out compete resident ones should be provided (Deaker et al., 2004). Roughely et al. (1993) have shown a linear relationship between number of rhizobia on a seed at sowing and the grain yield of narrow leafed lupin; with higher rhizobia populations resulting in better legume performance. The doubling of the rate of application in this study resulted in varied responses in terms of nodule numbers and fresh weight per plant and did not always result in the anticipated increase as per previous works. Over-inoculating or even inoculating seeds when not required (Herridge et al., 2002) has not been shown to have any negative effects. However, double rates of inoculation of both Biofix and Nitrozam in this study resulted in fewer nodules and less nodule fresh weight per plant in soya beans. This is an indication that the high populations of inoculant rhizobia provided through the double 
inoculation rate could easily have nodulated the plants and thereby prevented subsequent nodulation by the more effective indigenous strains (Waksman, 1952).

Legume inoculants can sometimes fail because of poor quality, poor survival during storage and death on the legume seed after inoculation. Both Biofix and Nitrozam inoculants carry rhizobia on sterilized peat. Both of these carry Bradyrhizobium japonicum Strain USDA 110. However, the Nitrozam, is locally produced and supplied fresh, while Biofix has the 6 month expiry period. In this study, we observed that both nodule numbers and nodule fresh weight per plant were higher when Nitrozam was used to inoculant soya beans than Biofix (Figures $1 \& 4$ ). In the absence of information on the storage conditions during transportation and prior to supply for evaluation of Biofix, we attribute the difference in performance between the two inoculants partly to the quality at planting. Biofix inoculants have previously been shown to fall short of the stated expiry period of six months (Balume, 2013). In addition, Biofix inoculants have been shown to carry additional contaminating microbes, which may interfere with the survival of rhizobia and subsequent root nodulation (Balume, 2013).

In conclusion, inoculating soya beans, groundnuts and cowpeas with non-indigenous inoculants resulted in varied responses across the crops but with a general increase in nodule number and fresh weights per plant. All assessed representative nodules were effective and showed pinkness across all the three legumes. There was no benefit to biological nitrogen fixation and above ground biomass yield due to inoculation. The results of this study point to the need to provide correct inoculants to farmers where required in order to obtain the full benefits of biological nitrogen fixation. A need exists to provide inoculants with appropriate and effective strains in sufficient numbers to farmers, when required. Further work under field conditions is recommended to confirm these findings.

\section{Acknowledgements}

We wish to thank the Soil Microbiology Laboratory at Mount Makulu Research Station for providing the legume inoculants used in this study. We also thank Ms Charity Nachalwe and Mr Gideon Musukwa for their technical support during the study.

\section{References}

Bala, A., Karanja, N., Murwira, M., Lwimbi, L., Abaidoo, R., \& Giller, K. (2011). Production and use of Rhizobial inoculants in Africa. p. 21 Retrieved from http://www.N2Africa.org

Balume K. M. I. (2013). Assessment of quality control of inoculants used on bean and soybean in eastern and central Africa (Master's thesis). University of Nairobi, Nairobi, Kenya.

Bremner, J. M., \& Mulvaney, C. S. (1982). Nitrogen-Total. In A. L Page, R. H. Miller \& D. R. Keeney (Eds). Methods of soil analysis, part 2: chemical and Microbiological properties (2nd edition). ASA, SSA, Madison, Wisconsin, USA.

Brockwell, J., Bottomley, P. J., \& Thies, J. E. (1995). Manipulation of rhizobia micro flora for improving legume productivity and soil fertility: a critical assessment. Plant and Soil, 174, 143-180. http://dx.doi.org/10.1007/BF00032245

Castro, S., Permigiani, M., Vinocur, M., \& Fabra, A. (1999). Nodulation in peanut (Arachi hypogaea L.) roots in the presence of native and inoculated rhizobia strains. Applied Soil Ecology, 13, 39-44. http://dx.doi.org/10.1016/S0929-1393(99)00016-5

Chianu, J. N., Nkonya, E. M., Mairura, F. S., Chianu, J. N., \& Akinnifesi, F. K. (2011). Biological nitrogen fixation and socioeconomic factors for legume production in sub-saharan Africa: a review. Agronomy for Sustainable Development, 31, 139-154. http://dx.doi.org/10.1051/agro/2010004

Compro II (2013). The building blocks for biofertiliser and biopesticides policymaking in Africa. Policy Brief, 2. Retrieved from http://www.iita.org/projects

Compro II (2012). Testing Rhizobia products on cowpea (RVU), common bean (RP), greengram (RVR) and groundnut (RA). Retrieved from http://www.compro2.org/outputs2.html

Deaker, R., Roughley, R. J., \& Kennedy, I. R. (2004). Legume seed inoculation technology-a review. Soil Biology \& Biochemistry, 36, 1275-1288.http://dx.doi.org/10.1016/j.soilbio.2004.04.009

Hassen, A. I., Bopape, F. L., Rong, I. H., \& Seane, G. (2014). Nodulation efficiency of Bradyrhizobium japonicum strain WB74 on soybean (Glycine max L. Merrill) is affected by several limiting factors. African Journal of Microbiology Research, 8(20), 2069-2076. http://dx.doi.org/10.5897/ajmr2014-6709

Herridge, D. (2002). Inoculants and Nitrogen Fixation of Legumes in Vietnam. ACIAR Proceedings 109e 
Herridge, D., Gemell, G., \& Hartley, E. (2002). Legume inoculants and quality control. In. D. Herridge (Ed.), Inoculants and Nitrogen Fixation of Legumes in Vietnam. ACIAR Proceedings 109e.

Howieson, J., \& Ballard, R. (2004). Optimising the legume symbiosis in stressful and competitive environments within southern Australia - Some contemporary thoughts. Soil Biology \& Biochemistry, 36(8), 1261-1273. http://dx.doi.org/10.1016/j.soilbio.2004.04.008

Keyser, H. H., Somasegaran, P., \& Bohlool, B. B. (1992).Rhizobial ecology and technology. In, F. B. Metting (Ed.). Soil Microbial Ecology. Applications in Agricultural and Environmental Management. (pp. 205-226). Marcel Decker, New York.

McDermott, T. R., \& Graham, P. H. (1990). Competitive ability and efficiency in nodule formation of strains of Bradyrhizobium japonicum. Applied and Environmental Microbiology, 56(10), 3035-3039.

Mungai N. W., \& Karubiu, N. M. (2010). Effectiveness of rhizobia isolates from Njoro soils (Kenya) and commercial inoculants in nodulation of common beans (Phaseolus vulgaris). Journal of Agriculture, Science and Technology, 12(1), 47-59.

Radtke, M. L. (2003). Environmental influences on Bradyrhizobium sp. Survival and nodulation potential on peanut (Master's thesis, Texas Tech University, Lubbock, Texas). Retrieved from https://repositories.tdl.org/tdl-ir/handle/2346/19500

Rennie, R. J. (1991). Canadian legume inoculants. Evolution of an industry. Report on the Expert Consultation on Legume Inoculant Production and Quality Control. FAO, Rome, pp. 51-60.

Ross, S., \& de Klerk, M. (April 2012). Groundnut Value Chain and Marketing Assessment in Eastern Province, Zambia. Conservation Farming Unit (CFU).

Roughley, R. J., Gemell, L. G., Thompson, J. A., \& Brockwell J. (1993). The number of Bradyrhizobiumsp. (Lupinus) applied to seed and its effect on rhizosphere colonisation, nodulation and yield of lupin. Soil Biology and Biochemistry, 25(10), 1453-1458. http://dx.doi.org/10.1016/0038-0717(93)90061-F

Rowell, D. L. (1994). Soil science: Methods and Applications. Addison Wesley Longman Singapore Publishers (pte) Ltd., England, UK.

Singleton, P. W., \& Tavares, J. W. (1986). Inoculation response of legumes in relation to the number of and effectiveness of indigenous rhizobium populations. Applied and Environmental Microbiology, 51(5), 1013-1018.

Tisdale, S. L., Nelson, W. L., \& Beaton, J. D. (1985). Soil fertility and fertilizers (4th ed.). Macmillam, USA.

Tu, J. C, Ford, R. E. \& Grau, C. R. (1970). Some factors affecting the nodulation and nodule efficiency in soybeans infected by Soybean Mosaic Virus. Phytopathology, 60, 1653-1656. http://dx.doi.org/10.1094/Phyto-60-1653

Unkovich, M., Herridge, D., Peoples, M., Cadisch, G., Boddey, B., Giller, K., Alves, B., \& Chalk, P. (2008). Measuring plant-associated nitrogen fixation in agricultural systems. ACIAR

Van Reeuwijk, L. P. (1992). Proceedings for soil Analysis (3rd Ed.) International soil Reference and Information Center (ISRIC), Wageningen, the Netherlands.

Waksman, S. A. (1952). Soil microbiology. John Wiley \& Sons, INC New York.

Woomer, P. L., Chamwada, M., Kaleha, C., Omondi, B., \& Ongoma, J. (2012). Smallholder Engagement in Kenya's Emerging Soybean Industry. N2Africa Program, CIAT-TSBF, Nirobi, Kenya.

\section{Copyrights}

Copyright for this article is retained by the author(s), with first publication rights granted to the journal.

This is an open-access article distributed under the terms and conditions of the Creative Commons Attribution license (http://creativecommons.org/licenses/by/3.0/). 